\title{
STUDY ON THE EFFECT OF ALGINATE, TYPE OF CROSS LINKERS, AND MUCOADHESIVE POLYMERS ON DRUG RELEASE FROM LOVASTATIN-LOADED MUCOADHESIVE CROSS-LINKED MICROBEADS
}

\author{
VENKATA RAMANA REDDY K*, NAGABHUSHANAM MV ${ }^{2}$ \\ ${ }^{1}$ Department of Pharmaceutics, KVK College of Pharmacy, Hyderabad, Telangana, India. ${ }^{2}$ Department of Pharmaceutics, Hindu College of \\ Pharmacy, Guntur, Andhra Pradesh, India. Email: srikanth.papa@gmail.com \\ Received: 31 August 2019, Revised and Accepted: 30 September 2019
}

\begin{abstract}
Objective: The aim of the current study is to prepare and lovastatin-loaded alginate microbeads were prepared using emulsification gelation internal method by the use of different cross-linking agents, polymer effect in different concentrations on drug release and its combination with hydrophilic polymers on drug release.
\end{abstract}

Methods: The effect of sodium alginate concentration and its combination with other hydrophilic polymers on particle size and shape, scanning electron microscopy (SEM) studies, entrapment efficiency, Fourier transform infrared (FTIR) analysis (FTIR), differential scanning calorimetry (DSC) studies, and X-ray diffraction (XRD) studies conducted to determine compatibility of drug and used excipients and in vitro drug release was studied. The efficiency of mucoadhesion strength of microbeads is determined by wash-off study.

Results: The optimum condition for preparation alginate beads and produces sustained release manner was occurred at 3\% polymer mixture. Infrared spectroscopic study confirmed the presence of compatibility between drug-polymer additives, good drug entrapment, and SEM studies prove microbeads were in spherical and rough particles. XRD and DSC were used to confirm successful entrapment of drugs into the alginates microbeads. The in vitro release profile could be altered notably by changing formulation parameters to give a sustained release of drug from the microbeads.

Conclusion: The kinetic modeling of the release data indicate that drug release from the microbeads follow anomalous transport mechanism and super Case-II transport mechanism and drug release is controlled by both swelling and relaxation of the polymer chains. The release of drug from formulation is $\mathrm{pH}$ dependent. This will help in overcoming the drawbacks of lovastatin with a short half-life, improves the bioavailability. The release kinetics of drug from the alginate beads followed zero order.

Keywords: Lovastatin, Sodium alginate, HPMC K4M, Emulsification internal gelation, Wash-off study, Mucoadhesive polymers.

(c) 2019 The Authors. Published by Innovare Academic Sciences Pvt Ltd. This is an open access article under the CC BY license (http://creativecommons. org/licenses/by/4. 0/) DOI: http://dx.doi.org/10.22159/ajpcr.2019.v12i12.35539

\section{INTRODUCTION}

Bioavailability is the real viewpoint to be considered the main key role in the planning of an oral dosage form essentially. It is the rate and extent of drugs that to be reached into the systemic circulation. Bioavailability relies on few factors which include drug permeability, aqueous solubility, and rate of dissolution, pre-systemic metabolism, and acceptability to efflux mechanism.

Drugs with a narrow absorption window in the gastrointestinal tract (GIT) have poor absorption [1]. The poor solubility is main cause of getting low bioavailability of numerous drugs. Biopharmaceutics Classification System (BCS) Class II drugs with reasonable permeability and poor solubility and is limited by the dissolution of drug step from various drug products [2]. Nowadays, $8 \%$ of new drug molecules have both high permeability and solubility, and $>60-65 \%$ of potential drug products were endure from rate of poor water solubility. It has turned out be extraordinary great in improving the rate of oral bioavailability of drugs by various strategies techniques forms and keep a challenge [3] for the formulation scientists because of problems lies in solubility concept.

The drugs fall under BCS Class II category [4] (low solubility and higher permeability) with an aim to improve both absorption and rate of oral bioavailability. All this causes an innovative attempt to formulate and design mucoadhesive drug delivery systems using lovastatin as the drug candidate. Lovastatin, a 3-hydroxy- 3-methylglutary coenzyme A reductase inhibitor, is a statin with well-known lipid-lowering effects that decreases even cardiovascular morbidity and mortality in patients with and without coronary artery diseases. It inhibits the production of cholesterol [5] by the liver. Lovastatin is poorly soluble in water that causes low bioavailability of drug. Its dissolution rate is often formed rate-limiting step in drug absorption [6,7]. It absorbs completely from small intestine and reaching $\mathrm{T}_{\max }$ in $4 \mathrm{~h}$. The drug bioavailability is $<5 \%$, highly lipophilic and having plasma half-life is $1-4 \mathrm{~h}$. Since because of this remark lovastatin is formulated in form of controlled drug delivery system. It undergoes extensive first-pass hydrolysis in liver into active metabolites such as $\beta$-hydroxy acid and 6-hydroxy derivative [8], and the absolute bioavailability of drug in systemic circulation is very less GRDDS might be suitable for lovastatin. Statins are suitable drug candidates for GRDDS. The various works have been reported on GRDDS employing statins to overcome the problems associated with oral administration. Oral controlled release multiple particulate dosage forms such as pellets, microparticles, and beads are forming more successful and important than single unit dosage form as these system allows more uniform distribution/spread in entire GIT and to avoid gastric emptying time, and different transient rate then release drug more uniformly that leads to more reproducible drug absorption and minimizes the incidence of local irritation than compared to single unit dosage form.

The current article describes the formulation and characterization of multiparticulate dosage form for controlled release of lovastatin and objective of research work is to improve biological half-life of lovastatin beads, release the drug from beads over extended period of time from 
optimized formulation, and targeted drug delivery to a specific site or a particular organ in the body. The effects of the polymer concentration, effect of various curing agents, encapsulation efficiency, effect of hydrophilic polymers on drug release, and release kinetics were also investigated. The ionotropic gelation technique was selected to prepare controlled release lovastatin alginate beads due to its easy accessibility, low economical, and its success with poor aqueous solubility drugs and the production of cross-linked beads.

\section{MATERIALS AND METHODS}

\section{Materials}

The pure drug lovastatin was generously obtained from Aurobindo Pharma Limited, Hyderabad, sodium alginate was purchased from HiMedia, Mumbai, hydroxypropyl methylcellulose (HPMC), Carbopol 934, calcium chloride $\left(\mathrm{CaCl}_{2} \cdot 2 \mathrm{H}_{2} \mathrm{O}\right)$, barium chloride $\left(\mathrm{BaCl}_{2} \cdot 2 \mathrm{H}_{2} \mathrm{O}\right)$, aluminum chloride $\left(\mathrm{AlCl}_{3} .6 \mathrm{H}_{2} \mathrm{O}\right)$, and ethanol, Qualigens, Mumbai, India, were obtained from Qualigens Fine Chemicals, Mumbai. All chemical agents used belonging to analytical grade or pharmaceutical quality.

\section{Equipments}

Digital electronic weighing balance, sonicator (Remi model, Mumbai, India), Sigma Blade Homogenizer (Remi model, India), tablet disintegrating test apparatus (USP model, India), dissolution test apparatus USP, model TDT-08L, El ectro Lab, Mumbai, India, Sonicator, Remi, India were obtained. Ultraviolet (UV)-visible spectrophotometer, Shimadzu, scanning electron microscope (SEM; S4100, Hitachi, Japan), X-ray diffractometer, Bruker spectrophotometer (Model-220, Germany), Syringe needle 23 G., etc., were obtained.

\section{Methods}

Preparation of lovastatin microbeads

The lovastatin microbeads were prepared by an emulsification internal gelation method [8]. Themicrobeads containing the lovastatin were prepared to employ sodium alginate alone and in blend with either sodium carboxy methylcellulose or HPMC K4M or Carbopol 934P. The homogenous polymer solution was prepared in distilled water $(15 \mathrm{ml})$ stirred magnetically with gentle heat. The drug and 5\% w/v crosslinking agent (calcium chloride/aluminum chloride/barium chloride) were added to the above viscous polymer solution slowly and mixed thoroughly by stirring sigma blade homogenizer until to form a fine, smooth viscous liquid which was then extruded through a syringe with a needle of size no. 23 into $100 \mathrm{ml}$ of light liquid paraffin which containing $1.5 \%$ span 80 and $0.2 \%$ glacial acetic acid. This discharge from needle was done slowly by keeping $10 \mathrm{~cm}$. Distance from surface of beaker and rotating was done with sigma blade mixture at a speed of $600 \mathrm{rpm}$ in a $500 \mathrm{ml}$ glass beaker. The above dispersion was continued at the same temperature and stirring was preceded for $30 \mathrm{~min}$. The microbeads were collected by decantation, and the product thus separated was washed 2 or 3 times with chloroform carefully to remove the traces of paraffin oil on the surface of formed soft microbeads. The product was then air-dried to obtain discrete lovastatin alginate microbeads. Various extents of core: coat materials, namely, 1:1, 1:1.5, 1:2, and 1:3 were used to prepare microbeads. To consider the effect of cross-linking agent, on the drug release from the beads, the process was replicated with different cross-linking agents (aluminum chloride/barium chloride).

\section{Determination of UV absorption maxima}

$10 \mathrm{mg}$ of pure lovastatin was dissolved in $10 \mathrm{ml}$ of methanol (primary stock solution - $1000 \mu \mathrm{g} / \mathrm{ml}$ ). From this primary stock solution, $1 \mathrm{ml}$ solution was pipette out into a $10 \mathrm{ml}$ standard volumetric flask and made it up to $10 \mathrm{ml}$ with the media (which is called as a secondary stock solution - $100 \mu \mathrm{g} / \mathrm{ml}$ ). From secondary stock solution, again $1 \mathrm{ml}$ was taken into another standard volumetric flask and made it up to $10 \mathrm{ml}$ with media (working solution $-10 \mu \mathrm{g} / \mathrm{ml}$ ). The above working solution was taken for checking the wavelength exactly.

\section{Angle of repose}

It was determined by utilizing a fixed funnel method. The tip of the funnel was fixed at a constant height (h) of $2.5 \mathrm{~cm}$ from the even surface.
The powder was gone through the funnel until the tip of the conical pile touches the tip of the funnel. The radius (r) of the base of the conical pile is estimated as in $\mathrm{cm}$. It is resolved using the following formula,

$$
\text { Angle of repose }(\theta)=\operatorname{Tan}^{-1}(\mathrm{~h} / \mathrm{r})
$$

\section{Hausner's ratio}

It is connected to the flowability of the blend of beads. On the off chance that value is $<1.25$, then it suggests good flow, and it is $>1.5 \%$; it indicates poor flow property of beads mixture.

It was calculated by the following formula,

$$
\text { Hausner ratio }=\rho_{\mathrm{t}} / \rho_{\mathrm{b}}
$$

Where, $\rho_{\mathrm{b}}$ is the bulk density and $\rho_{\mathrm{t}}$ is the tapped density.

\section{Carr's index}

It gives data about the compressibility of cross-linked lovastatin alginate beads, and it is often used in sign of flowability of dry beads. In the event, if beads possess free-flowing property then cars index is having a small value. The value of Carr's index having $>25$, then it implies beads posses' poor flowability character.

\section{Size distribution and size analysis}

For determination of size distribution analysis, $200 \mathrm{mg}$ of the lovastatin alginate microbeads of different sizes in a batch were subjected to sieving method, using a range of standard sieves grades and arranged one by one and run the machine continuously according to the defined procedure. The amount of uninformed beads retained on different sieves was taken out and weighed exactly [9]. The mean particle size of the microbeads was calculated by the following equation.

$$
\text { Mean particle size }=\frac{\sum_{\text {Weight fracion })}^{(\text {Mean particle sixe of fraction } \times}}{\sum(\text { Weight fraction })}
$$

\section{Percentage of yield}

Percent yield is the percent ratio of actual yield to the theoretical yield. It is calculated to be the experimental yield divided by theoretical yield multiplied by $100 \%$. Mathematically, it is computed from following equation.

$$
\text { Percentage of yield }=\frac{\text { Practical yield }}{\text { Theroteical yield }} \times 100
$$

\section{Estimation of drug content of microbeads}

Accurately $100 \mathrm{mg}$ of microbeads were weighed and transferred into a mortar. Powdered and dissolved in $100 \mathrm{ml}$ of $\mathrm{pH} 6.8$ phosphate buffer, suitably diluted, the absorbance of the resulting solution was measured at $238 \mathrm{~nm}$ for lovastatin.

\section{Entrapment efficiency of microbeads}

Entrapment efficiency was resolved using the formula. For calculation of drug content, $10 \mathrm{mg}$ of beads were placed in $100 \mathrm{ml}$ of 6.8 phosphate buffer for complete swelling at $37^{\circ} \mathrm{C}$. The lovastatin based alginate beads was crushed in a glass mortar with pestle and the above solution was then kept for $2 \mathrm{~h}$ to extract the drug completely and centrifuged to separate polymeric debris using centrifuge apparatus for $30 \mathrm{~min}$. The solution was filtered; the clear supernatant solution was measured for lovastatin content using a UV-visible spectrophotometer at $238 \mathrm{~nm}$ [10].

$$
\begin{aligned}
& \text { Estimated percentage } \\
& \text { Entrapment efficeincy }=\frac{\text { drug content }}{\text { Theoritical percentage }} \times 100 \\
& \text { drug content }
\end{aligned}
$$




$$
\text { Drug loading }=\frac{\text { Total amount of drug in microbeads }}{\text { Weight of microbeads }} \times 100
$$

Estimated percent drug content was determined from the analysis of $100 \mathrm{mg}$ microbeads, and the theoretical percent drug content was calculated from the utilized core: coat ratio in the formulation of microbeads.

\section{Fourier transform infrared (FTIR) analysis}

To study the possible drug-polymer interactions, the pellets were prepared at high compaction pressure by utilizing $\mathrm{KBr}$ the proportion of test to $\mathrm{KBr}$ was 1:1000. The pellets arranged were examined under FTIR machine (Bruker, Japan), and the spectra were taken. In each case, the spectra were compared with the pure drug spectrum to detect the interactions between drug and all used excipients [11,12].

\section{Differential scanning calorimetry (DSC) studies}

The thermal behavior of the lovastatin alginate beads was traced out using a thermal analyzer unit (NETZSCH, Japan). The DSC analysis of pure drug, drug-loaded microbeads, and drug-free microbeads was carried out by recording thermograms for 5-15 mg samples at a heating rate $10 \mathrm{~K} / \mathrm{min}$ from 0 to $300^{\circ} \mathrm{C}$ temperature range and run under nitrogen flow of $25 \mathrm{ml} / \mathrm{min}$. The samples were fixed in aluminum crucibles, with the lid perforated, before the test [13]. An empty aluminum crucible was used as the reference, and then thermograms were recorded.

\section{Powder X-ray diffraction (XRD) studies}

The crystalline nature of drug, polymer and the formulations were determined at $2 \theta^{\circ} \mathrm{C} / \mathrm{min}$. Scanning was done at rate, $40 \mathrm{KV}$, and $30 \mathrm{~mA}$. The crystallinities of lovastatin and lovastatin-loaded alginate microbeads were assessed by XRD measurement recorded for pure lovastatin, and lovastatin-loaded alginate microbeads, using an X-ray diffractometer (model PW/1710, Poland). Scanning was performed up to $2 \theta$ range somewhere in the range of $2^{\circ}$ and $90^{\circ}$ utilizing Ni-filter [14].

\section{SEM studies}

The surface morphology of microbeads was explored using SEM (USA model). A known quantity of dried alginate beads were placed or spread on a brass stub using double-sided adhesive tape and made electrically conductive by coating with a thin layer of gold, and SEM images were seen at various accelerating voltage $[15,16]$. These test samples were then randomly scanned, and photomicrographs were taken care.

\section{In vitro wash-off test for mucoadhesive microbeads}

The mucoadhesive property of the microbeads was assessed by conducting an in vitro adhesive testing technique is known as the washoff method. A bit of goat intestinal mucous membrane $(2 \mathrm{~cm} \times 2 \mathrm{~cm})$ was mounted onto glass slides of $3 \times 1$ inch with a thread glass slide and was connected with suitable support. Around 100 microbeads have been spread over wet rinsed tissue specimens, and from there on the support was clung to the shaft of a USP tablet disintegrating test machine (Electro Lab, ED 2AL). The disintegrating test machine containing the tissue specimen was given regular and down movement continuously in a beaker of disintegration apparatus and maintained temperature at $37 \pm 0.5^{\circ} \mathrm{C}$ taken in a beaker. Toward the finish of $1 \mathrm{~h}$ and later at hourly intervals as long as up to $8 \mathrm{~h}$, the machine was halted, and the number of microbeads as yet adhering onto the mucous membrane was counted. The test was performed in both $0.1 \mathrm{~N}$ HCL acid for first $2 \mathrm{~h}$ and in later acid medium is replaced with fresh $\mathrm{pH} 6.8$ phosphate buffer medium and run the test for next 8-10 h.

\section{In vitro drug release studies}

The In vitro release rate of lovastatin alginate microbeads was evaluated by dissolution test apparatus (USP model) basket type. The study was carried out in both $\mathrm{pH} 1.2$ for $2 \mathrm{~h}$ and buffer solution $\mathrm{pH} 6.8$ until the end of the study at atmosphere of $37 \pm 0.5^{\circ} \mathrm{C}$ [17]. The rotation speed of the paddle was fixed at $100 \mathrm{rpm}$. The in vitro release studies of lovastatin-loaded microbeads were tested out in simulated gastric fluids to mimic body physiology in terms of different $\mathrm{pH}$. The equivalent amounts of $20 \mathrm{mg}$ of dried cross-linked lovastatin alginate microbeads were suspended in $900 \mathrm{ml}$ of 6.8 phosphate buffer dissolution medium. At fixed time intervals, $5 \mathrm{ml}$ of sample was withdrawn and same amount was replaced to maintain sink conditions, and withdrawn samples were subjected to proper dilutions with same fresh phosphate buffer solution and examined for drug absorbance measured at $238 \mathrm{~nm}$ using a UV-visible double beam spectrophotometer. The concentration of lovastatin in the test samples was corrected and calculated using regression equation of the calibration curve.

\section{Stability studies}

Stability studies were done for lovastatin beads as indicated by standards of ICH protocol rules. The samples of known weight were weighed in two sets and wrapped in a good quality butter paper and put in sterilized petri dish plates. These containers were put away precisely at the ambient humid condition at room temperature $\left(27 \pm 2^{\circ} \mathrm{C}\right)$ and elevated temperature $\left(45 \pm 2^{\circ} \mathrm{C}\right)$ for the range of 3 months precisely. At that point, alginate beads were observed for various physical changes mainly in shape, size, softness, drug entrapment, and drug release. The drug content was estimated for 3 months once according to the characterized standard strategy. The drug samples were assessed at $238 \mathrm{~nm}$ for further scanning to watch/identify any possible spectral changes even on a small level, and any progressions mean they have been accounted for.

\section{Release kinetics}

To study the release kinetics, information acquired from in vitro dissolution study was fitted in different kinetic models: Zero-order as cumulative percent of drug released versus time, first-order as log cumulative percentage of drug remaining versus time, and Higuchi's model as a cumulative percent drug released versus square root of time, Hixon-Crowel depicts the drug release from systems when there is a change in both diameters of particles and surface area.

To decide the drug release mechanism [18], various equations mentioned above employed in investigation and Korsmeyer-Peppas model because of their effortlessness, simplicity, and simple appropriateness. The information was fitted into Korsmeyer and Peppas equation as cumulative log percentage of drug released versus log time, and the exponent $n$-value was determined from the slope of the straight line. For slab matrix, if the exponent is 0.5 , then the diffusion mechanism is Fickian; if $0.5<\mathrm{n}<1.0$, then it an indication of anomalous transport. If $\mathrm{n}$ is 1.0, it is Case II transport, and if $n>1.0$, at that point it is affirmed as super Case II transport or non-Fickian diffusion.

\section{RESULTS AND DISCUSSION}

Determination of $\lambda_{\max }$ for characterization of pure lovastatin by UV spectroscopy, it is important to know the wavelength of maximum absorption, i.e., $\lambda_{\max }$. The UV spectrum of pure lovastatin in methanol solvent was taken and is shown in Fig. 1. The results of $\lambda_{\max }$ of lovastatin in methanol were observed at wavelength of $238 \mathrm{~nm}$ exactly on scanning from 200 to $400 \mathrm{~nm}$.

Effect of sodium alginate concentration on yield, drug entrapping efficiency (DEE), and particle size

All the obtained microbeads qualified in micromeritics properties as they are posses' results within described limits, i.e., Carr's index of the prepared beads was found to be below 18\% and Hausner's ratio was nearest value of 1.2. And angle of repose value possess below the value of $27.37 \pm 0.05$, from based on above result it was concluded that the cross-linked beads have qualified with good flow properties and showed all micromeritics values were shown in Table 1 . The concentration of sodium alginate has an extraordinary influence on yield, particle size, drug entrapment efficiency and drug content were shown in Table 2. The 
batches LF1-LF4 only sodium alginate used without any combination with hydrophilic polymers and drug ratio is same all batches. To study the influence of combination as a coat ratio with different concentrations ranging from smaller to higher concentration sodium alginate used with different hydrophilic polymers in equal proportions. Based on analytical and statistical data, it was clearly proved as it forms a directly proportional relationship toward drug release when coat ratio was increased. The concentration of drugs in all batches was same, but coat ratio was increased from $1,1.5,2$, and 3 . As the coat ratio increased from 1 to $3 \mathrm{w} / \mathrm{v}$, the percentage of drug release was found to be delayed and this occurs due to the reason of increase in viscosity of physical mixture on increasing concentration of polymers. The ratio of core: coat has major influence on all physical parameters and on micromeritics properties. The number of cross-linking sites gets increases within

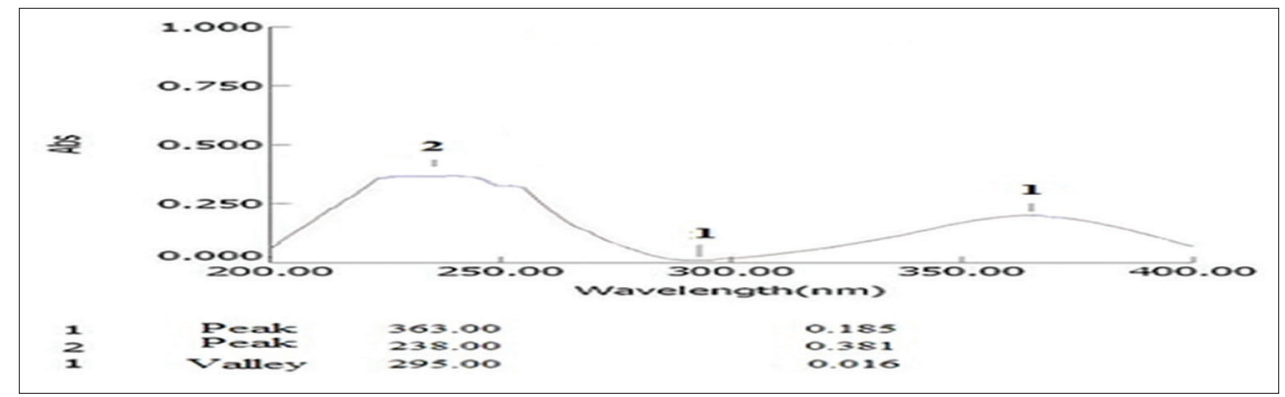

Fig. 1: Ultraviolet spectra of pure lovastatin

Table 1: Flow properties of lovastatin based sodium alginate microbeads

\begin{tabular}{|c|c|c|c|c|c|}
\hline Formulation & $\begin{array}{l}\text { Angle of } \\
\text { repose }(\theta)\end{array}$ & $\begin{array}{l}\text { Bulk density } \\
\left(\mathrm{g} / \mathrm{cm}^{3}\right)\end{array}$ & $\begin{array}{l}\text { Tapped } \\
\text { density }\left(\mathrm{g} / \mathrm{cm}^{3}\right)\end{array}$ & $\begin{array}{l}\text { Carr's } \\
\text { index (\%) }\end{array}$ & $\begin{array}{l}\text { Hausner's } \\
\text { ratio }\end{array}$ \\
\hline LF1 & $26.84 \pm 0.02$ & $0.319 \pm 0.004$ & $0.362 \pm 0.013$ & $11.87 \pm 0.08$ & $1.130 \pm 0.02$ \\
\hline LF2 & $27.23 \pm 0.05$ & $0.351 \pm 0.007$ & $0.393 \pm 0.011$ & $10.68 \pm 0.06$ & $1.119 \pm 0.03$ \\
\hline LF3 & $25.62 \pm 0.06$ & $0.255 \pm 0.006$ & $0.291 \pm 0.007$ & $12.37 \pm 0.04$ & $1.142 \pm 0.06$ \\
\hline LF4 & $25.28 \pm 0.04$ & $0.320 \pm 0.011$ & $0.370 \pm 0.009$ & $11.89 \pm 0.06$ & $1.134 \pm 0.08$ \\
\hline LF5 & $27.19 \pm 0.07$ & $0.905 \pm 0.03$ & $1.059 \pm 0.03$ & $15.7 \pm 0.05$ & $1.17 \pm 0.04$ \\
\hline LF6 & $25.13 \pm 0.03$ & $0.912 \pm 0.05$ & $1.058 \pm 0.08$ & $14.8 \pm 0.04$ & $1.16 \pm 0.03$ \\
\hline LF7 & $22.84 \pm 0.05$ & $0.928 \pm 0.04$ & $1.067 \pm 0.04$ & $13.6 \pm 0.07$ & $1.15 \pm 0.05$ \\
\hline LF8 & $21.17 \pm 0.04$ & $0.941 \pm 0.06$ & $1.072 \pm 0.03$ & $12.8 \pm 0.05$ & $1.14 \pm 0.07$ \\
\hline LF9 & $27.67 \pm 0.03$ & $0.770 \pm 0.02$ & $0.924 \pm 0.05$ & $15.8 \pm 0.03$ & $1.20 \pm 0.06$ \\
\hline LF10 & $25.11 \pm 0.06$ & $0.784 \pm 0.05$ & $0.925 \pm 0.04$ & $14.6 \pm 0.07$ & $1.18 \pm 0.03$ \\
\hline LF11 & $23.55 \pm 0.04$ & $0.796 \pm 0.07$ & $0.923 \pm 0.06$ & $13.9 \pm 0.04$ & $1.16 \pm 0.07$ \\
\hline LF12 & $22.16 \pm 0.05$ & $0.812 \pm 0.04$ & $0.926 \pm 0.08$ & $12.8 \pm 0.07$ & $1.14 \pm 0.04$ \\
\hline LF13 & $27.14 \pm 0.07$ & $0.528 \pm 0.04$ & $0.623 \pm 0.03$ & $13.88 \pm 0.05$ & $1.16 \pm 0.07$ \\
\hline LF14 & $27.37 \pm 0.05$ & $0.492 \pm 0.07$ & $0.584 \pm 0.04$ & $14.82 \pm 0.06$ & $1.14 \pm 0.05$ \\
\hline LF15 & $26.32 \pm 0.04$ & $0.571 \pm 0.04$ & $0.588 \pm 0.07$ & $15.93 \pm 0.07$ & $1.18 \pm 0.07$ \\
\hline LF16 & $25.16 \pm 0.06$ & $0.512 \pm 0.03$ & $0.612 \pm 0.06$ & $16.47 \pm 0.03$ & $1.19 \pm 0.05$ \\
\hline LF17 & $23.42 \pm 0.77$ & $0.623 \pm 0.93$ & $0.724 \pm 0.15$ & $13.95 \pm 0.02$ & $1.16 \pm 0.56$ \\
\hline LF18 & $22.68 \pm 0.80$ & $0.686 \pm 0.09$ & $0.790 \pm 0.18$ & $13.16 \pm 0.01$ & $1.15 \pm 0.32$ \\
\hline
\end{tabular}

All readings were taken in triplicate $(\mathrm{n}=3)$. Mean \pm standard deviation

Table 2: Core: coat ratio, percentage yield, mean particle size, drug content, and percent entrapment efficiency of lovastatin microbeads

\begin{tabular}{lllllll}
\hline Polymers used & $\begin{array}{l}\text { Formulation } \\
\text { code }\end{array}$ & $\begin{array}{l}\text { Core: coat } \\
\text { ratio }\end{array}$ & Yield (\%) & $\begin{array}{l}\text { Average particle } \\
\text { size }(\boldsymbol{\mu m})\end{array}$ & $\begin{array}{l}\text { Drug } \\
\text { content }\end{array}$ & $\begin{array}{l}\text { Percentage } \\
\text { entrapment efficiency }\end{array}$ \\
\hline Sodium alginate & LF1 & $1: 1$ & 94.52 & $146.79 \pm 0.06$ & $44.76 \pm 0.04$ & $89.52 \pm 0.06$ \\
& LF2 & $1: 1.5$ & 96.43 & $165.33 \pm 0.04$ & $37.12 \pm 0.02$ & $92.80 \pm 0.04$ \\
& LF3 & $1: 2$ & 97.68 & $174.81 \pm 0.06$ & $31.16 \pm 0.04$ & $94.42 \pm 0.03$ \\
Sodium alginate+HPMC K4M & LF4 & $1: 3$ & 98.16 & $188.24 \pm 0.07$ & $23.64 \pm 0.08$ & $94.56 \pm 0.05$ \\
& LF5 & $1: 1$ & 92.46 & $140.46 \pm 0.03$ & $46.38 \pm 0.05$ & $92.76 \pm 0.04$ \\
& LF6 & $1: 1.5$ & 94.32 & $156.12 \pm 0.08$ & $37.45 \pm 0.04$ & $93.62 \pm 0.06$ \\
& LF7 & $1: 2$ & 96.87 & $167.88 \pm 0.04$ & $31.35 \pm 0.06$ & $94.05 \pm 0.03$ \\
Sodium alginate+Carbopol 934P & LF8 & $1: 3$ & 97.34 & $157.63 \pm 0.07$ & $24.05 \pm 0.03$ & $96.24 \pm 0.04$ \\
& LF9 & $1: 1$ & 93.34 & $147.84 \pm 0.05$ & $45.83 \pm 0.07$ & $91.60 \pm 0.04$ \\
& LF10 & $1: 1.5$ & 95.67 & $163.17 \pm 0.06$ & $36.93 \pm 0.03$ & $92.32 \pm 0.07$ \\
Sodium alginate+Na. & LF11 & $1: 2$ & 97.39 & $172.88 \pm 0.04$ & $31.21 \pm 0.02$ & $93.63 \pm 0.04$ \\
carboxymethyl cellulose & LF12 & $1: 3$ & 98.28 & $189.65 \pm 0.03$ & $23.77 \pm 0.04$ & $95.08 \pm 0.06$ \\
1100-1900 cps & LF13 & $1: 1$ & 93.34 & $147.84 \pm 0.63$ & $45.80 \pm 0.84$ & $91.60 \pm 0.67$ \\
& LF14 & $1: 1.5$ & 95.67 & $163.17 \pm 0.58$ & $36.93 \pm 0.29$ & $92.32 \pm 0.24$ \\
Sodium alginate+HPMC K4M & LF15 & $1: 2$ & 97.39 & $172.83 \pm 0.27$ & $31.25 \pm 0.37$ & $93.63 \pm 0.27$ \\
Sodium alginate+HPMC K4M & LF16 & $1: 3$ & 98.29 & $189.67 \pm 0.85$ & $23.77 \pm 0.77$ & $95.08 \pm 0.57$ \\
\end{tabular}

*Batches LF1-LF16 cured with 5\% Alcl ${ }^{3+}$ with different polymers only and LF17 and LF18 batches containing sodium alginate with HPMC K4M. And that cured with 5\% $\mathrm{w} / \mathrm{v}$ of $\mathrm{Bacl}^{2+}$ and $5 \% \mathrm{Cacl}^{2+} \mathrm{w} / \mathrm{v}$. *All readings were taken in triplicate manner, i.e., $\mathrm{n}=3$. HPMC: Hydroxypropyl methylcellulose 
aluminum cross-linked alginate beads on addition in the amount of sodium alginate polymer for the first four batches (LF1-LF4). From LF5 to LF16 batches, sodium alginate was mixed with different polymers such as hydroxypropyl methylcellulose K4M, Carbopol 934P, and sodium carboxymethyl cellulose 1100-1900 cps in equal proportions that were mixed with $\mathrm{Alcl}^{3+}$ (acts as curing agent) which are shown in Table 2. The incorporation efficiency increased progressively with increasing sodium alginate concentration as well. The higher concentration of coat ratio $(3 \% \mathrm{w} / \mathrm{v})$ physical mixture containing sodium alginate $1.5 \% \mathrm{w} / \mathrm{v}: 1.5 \%$ $\mathrm{w} / \mathrm{v}$ other hydrophilic polymers naming hydroxypropyl methylcellulose K4M, Carbopol 934P, and sodium carboxymethylcellulose polymer 1100-1900 cps produces the greater viscous solution, which shaped bigger and stable microbeads than compared to $1,1.5$, and $2 \% \mathrm{w} / \mathrm{v}$ of sodium alginate with other polymers concentration (LF5-LF18 batches). This improved consistency in solution could affect the pore size on the surface of beads, and accordingly drug release becomes moderate slow, small beads $(1,1.5$, and $2 \% \mathrm{w} / \mathrm{v}$ of coat ratio in equal proportions) turns into larger microbeads (3\% w/v of coat ratio). The normal average bead particle size range was observed to be in the range of $140.46 \pm 0.03-189.65 \pm 0.85$ in $\mu \mathrm{m}$.

The average DEE was found to be in the range of $89.52 \pm 0.06$ $96.24 \pm 0.04$ in percentage. The higher DEE, i.e., $96.24 \pm 0.04$ (LF8 batch) will be accomplished more at the higher concentration of sodium alginate with HPMC K4M in equal ratios. When compared with high concentration of sodium alginate, i.e., $1.5 \mathrm{w} / \mathrm{v}$, this may be attributed to the maximum number of existing cross-linking sites, i.e., active aluminum-binding sites in the sodium alginate polymeric chains and the greater/maximum intensity of cross-linking network takes place as the amount of sodium alginate concentration was enhanced from 1 to $3 \% \mathrm{w} / \mathrm{v}$. The drug entrapment efficiencies were generally greater for the formulations that cross-linked with Alcl ${ }^{3+}$ (LF1-LF16 batches) and $\mathrm{BaCl}^{2+}$ (LF17) as curing agents at $5 \% \mathrm{w} / \mathrm{v}$ as compared to the beads cross-linked with $\mathrm{CaCl}^{2+}$ at same concentration (LF18). The reason may be attributed to the formation of non-porous alginate beads (LF18). Due to increase in the maximum intensity of cross-linking network in the presence of $\mathrm{Alcl}^{3+}$ and $\mathrm{Bacl}^{2+}$ alone acts as hardening agent which restrict the diffusion of the drug out of the beads into the emulsifying medium during mixing. The low incorporation efficiency was observed in lovastatin-based alginate beads that cross-linked with $\mathrm{CaCl}^{2+}$ could be assigned the formation of slight porous along surface of the soft cross-linked beads, in turn, which promotes the diffusion of the drug out of the soft beads during the homogenization.

A variety of polymers have been used in conjunction with sodium alginate to modulate drug loading, shape, surface, DEE, and drug release kinetics profiles. Formulations that demonstrated the greater drug entrapment efficiencies were observed when sodium alginate used in higher concentrations in combination with other hydrophilic polymers with equal proportions. The average percentage of yield was found to be in the range of 92.46-98.28. This maximum yield of production is may be due to all the polymer is available for gelation process into a cross linking agent during emulsification process.

\section{Effect of various cross-linking agents}

The cross-linking is achieved by the ionic interaction between $\mathrm{Ca}^{2+}$ ions and the carboxyl groups of the guluronic acid residues of two neighboring alginate chains that form tight/compact cross-linking network [19].

In the current article, three different curing agents at $5 \% \mathrm{w} / \mathrm{v}$ were used, of which two were divalence, and one compound is trivalency in nature. The decrease in size of beads will observe when aluminum chloride used than barium chloride and calcium chloride at same concentration. Bacl ${ }^{2+}$ ion cross-linked blends have relatively more cross-linked network structure and hence they absorb lower water uptake due to tight structure in the intermolecular chain, so they possess minimum swelling rate. In case of trivalent aluminum chloride cross-linked blends, the beads swell little as compared to bivalent cations $\left(\mathrm{Ca}^{2+}\right.$ and $\left.\mathrm{Ba}^{2+}\right)$. The drug diffusion from the matrix too was fast in case of matrix cross-linked with $\mathrm{Cacl}^{2+}$ and very slow in the matrix cross-linked with $\mathrm{Alcl}^{3+}$. The explanation of above observations could be related to the mechanism of bonding of calcium chloride, barium chloride, and aluminum chloride cations with the alginate anions. Since calcium and barium are bivalent, its bonding is expected to occur in a planar two-dimensional network manner.

The trivalent aluminum cation is expected to form a three-dimensional network structure with alginate structure. On ionic gelation method, in contrast to $\mathrm{Bacl}^{2+}$ and $\mathrm{Cacl}^{2+}$, one extra cross-linking site available for $\mathrm{Alcl}^{3+}$ and it would be showing extra beneficial effects in physical properties such as drug entrapment, yield, size, shape, and on release of drug. Since aluminum ions have an extra positive charge compared to divalent calcium and barium ions; thus, each molecule of aluminum is able to bind to one more alginate molecule. Because of this, aluminum chloride was capable of forming a gel more quickly and which did not allow the dissolution medium to quickly enter the films [20]. Thus, the dissolution rate compared to the formulation containing the same number of moles of calcium chloride and barium chloride was lower. In case of aluminum chloride, the greater of cross-linking occurs so that compact/rigid beads formed and get shrinks or undergoes contraction in size on cross-linking mechanism. In addition to this, aluminum chloride was capable of forming a gel more quickly and which did not allow the dissolution medium to quickly enter the beads.

The degree of cross-linking depends on the ability of the cross-linking depends on the ionic size. The diffusion ability is a function of the ionic size. Since the barium chloride ${ }^{2+}$ has a radius of $1.35 \AA$ compared to 0.97 $\AA$ for $\mathrm{Cacl}^{2+}$ ion, the $\mathrm{Bacl}^{2+}$ ions are expected to fill a larger space between the alginate molecules producing a tight arrangement at the surface with smaller voids so that reduced swelling rate is thus observed. The smaller size of calcium cations compared with barium cations is responsible for less tight structure on the surface, which allows the ions to diffuse to depth and crosslink at a minimum level. Aluminum has a radius of 0.68 $\AA$ value than above two; it forms work small size with tight cross-linking network due to formation of three-dimensional network; it develops and forms strong compact beads with rigid nature on its surface.

\section{The FTIR studies}

The spectrum of the optimized batch was clearly composed of almost the same identical peaks of lovastatin, and its characteristic peaks were not affected by the presence of all used excipients used in the formulation of cross-linked alginate beads. The optimized batch showed no major shifting and no loss of functional groups between lovastatin. The characteristics peaks related to pure lovastatin were retained with slight deviations in frequency ranges Figs. 2 and 3. It suggests the absence of drug-polymer interaction and indicating the stability of lovastatin. The different frequencies of functional groups are displayed in the following Table 3.

All FTIR spectrums were derived from single average scans that were processed in the region of $500-4000 \mathrm{~cm}^{-1}$ at spectral resolution of nearly $2 \mathrm{~cm}^{-1}$ and ratio against background interfere gram. The pure lovastatin drug shows peak at $1067.17 \mathrm{~cm}^{-1}$ (C-C symmetric bend), $1239 \mathrm{~cm}^{-1}$ (C-0,

Table 3: Comparison of Fourier transform infrared frequency ranges of pure lovastatin and optimized batch

\begin{tabular}{lll}
\hline Functional groups & $\begin{array}{l}\text { Pure } \\
\text { drug }\end{array}$ & $\begin{array}{l}\text { Optimized } \\
\text { batch }\end{array}$ \\
\hline O-H stretching & 3441.53 & 3442.23 \\
Olefinic C-H stretching & 3193.44 & 3197.63 \\
Methyl C-H asymmetric stretching & 2933.68 & 2969.82 \\
Carbonyl Stretching & 1705.84 & 1706.38 \\
C-O-C asymmetric bending & 1277.66 & 1278.10 \\
C-O-C lactone symmetric bending & 1067.17 & 1066.19 \\
Tri-substituted olefinic C-H groups & 863.19 & 863.44 \\
Alcohol C-OH stretch & 993.89 & 994.62 \\
\hline
\end{tabular}




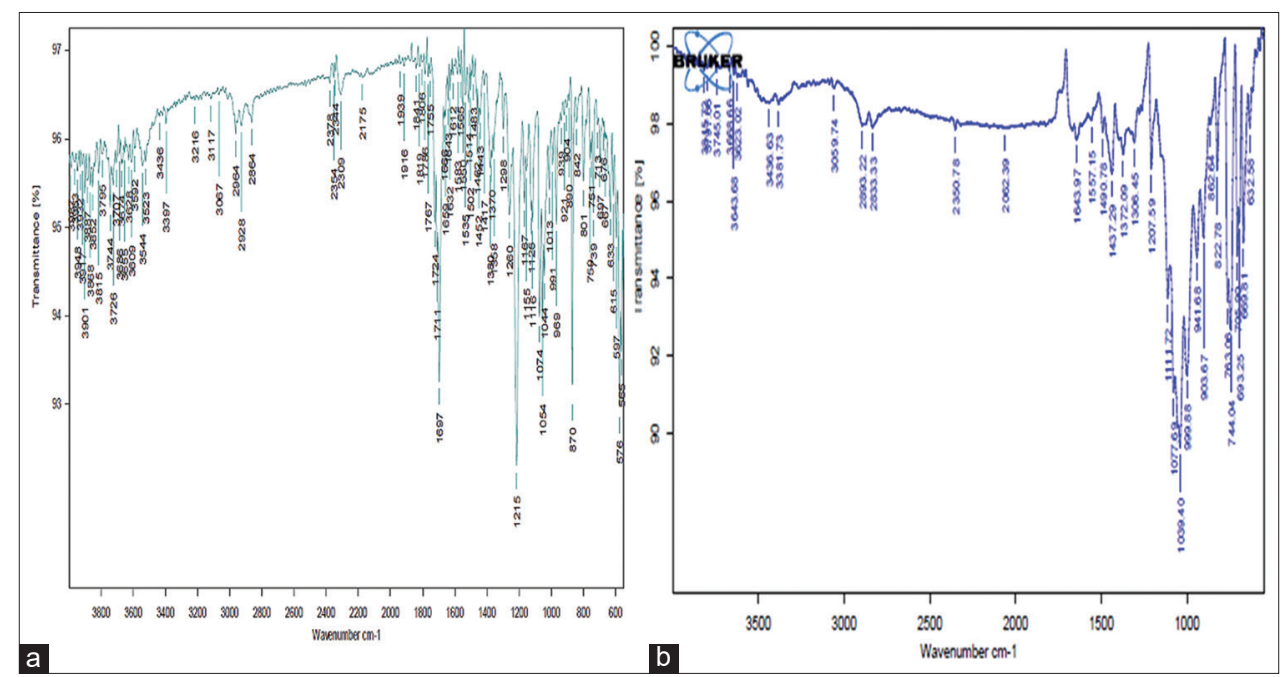

Fig. 2: (a and b) Fourier transform infrared spectra of pure lovastatin (left side) and physical mixture containing lovastatin and sodium alginate (right side)

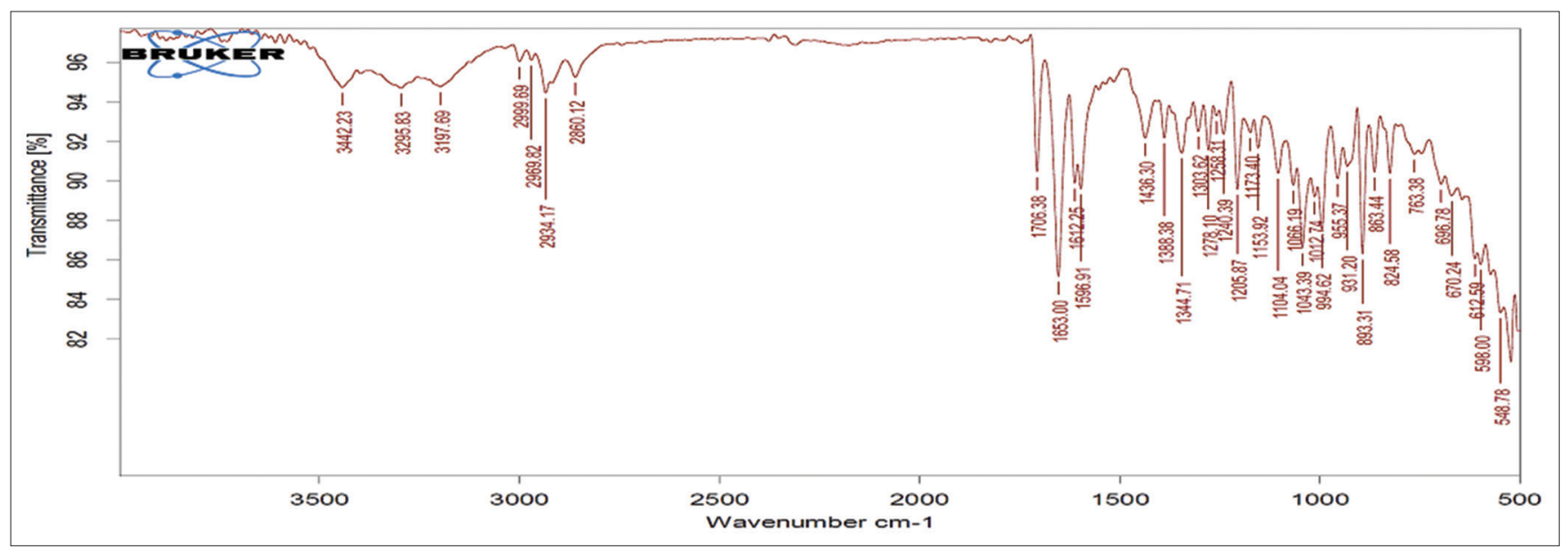

Fig. 3: Fourier transform infrared spectra of optimized batch

alcoholic bending), $1388.07 \mathrm{~cm}^{-1}$ is designate to the stretching vibration of the $-\mathrm{C}-\mathrm{H}$, methylene asymmetric stretching, peak at $1596.27 \mathrm{~cm}^{-1}$ which indicates asymmetric stretching vibration of carbonyl functional group, peak at $1277.66 \mathrm{~cm}^{-1}$ represents presence of lactone, ester C-O-C asymmetric bend, peak at $1435.35 \mathrm{~cm}^{-1}$ as it proves presence of methyl asymmetric bending, the existence of lactose, $\mathrm{C}=0$ carbonyl stretching vibration confirmed peaks at 2970.02 and 1744.73 . The appearance of peak at $1705.84 \mathrm{~cm}^{-1}$ band is given to the stretching vibration of saturated lactone, and peak at $3441.53 \mathrm{~cm}^{-1}$ band is assigned to the alcohol-OH stretching vibration. In case of HPMC peak observed at 3442 $\mathrm{cm}^{-1}$ indicating the presence of primary alcoholic group present and the band at $3442 \mathrm{~cm}^{-1}$ is attributed to the presence of hydroxyl stretching in the HMPC and microsphere samples. Another important peak appears at $2934 \mathrm{~cm}^{-1}$ recommends the existence of an aliphatic molecule. Furthermore, notable was a distinguishable peak at $1706.38 \mathrm{~cm}^{-1}(\mathrm{C}=0$ stretching), which was detected in the modified microsphere samples this observation indicated that the acidic esterification reaction between sodium alginate and HPMC had occurred.

\section{SEM studies}

The microspheres were somewhat resemble in a spherical in shape with grainy and wrinkled surfaces, discrete microbeads (Fig. 4).

\section{DSC studies}

For the structural, crystal, and physical state characterization of the drug, DSC studies were investigated. Lovastatin had a particular major

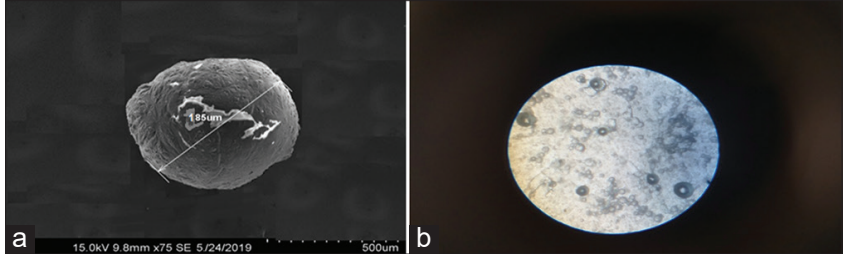

Fig. 4: ( $a$ and $b$ ) Scanning electron microscope photograph of lovastatin microbead (left image) and microscopic photographic image of microbeads (right image)

sharp endothermic peak at about $174.8^{\circ} \mathrm{C}$ due to its own melting point. Lovastatin existed as a crystalline in state. In contrast, in optimized batch, in optimized batch shows slight broadening and shifting of the endothermic peak which is due to melting effect of the addition of HPMC K4M. Lovastatin melting peak totally disappeared in the DSC thermogram of loaded microbeads, which gives evidence the absence of crystalline drug in the microbeads samples, at least at the particle surface level. Therefore, it could be reported that lovastatin in the microbeads was in amorphous phase of a solid solution or molecular dispersion state in the polymer matrix after the production. The appearance of the particular peak in lovastatin loaded in sodium alginate polymer at $340.9^{\circ} \mathrm{C}$ and $355.2^{\circ} \mathrm{C}$ as a extra peaks observed in lovastatin-loaded HPMC K4M microbeads (LF8). The less sharp endothermic peak appeared at 


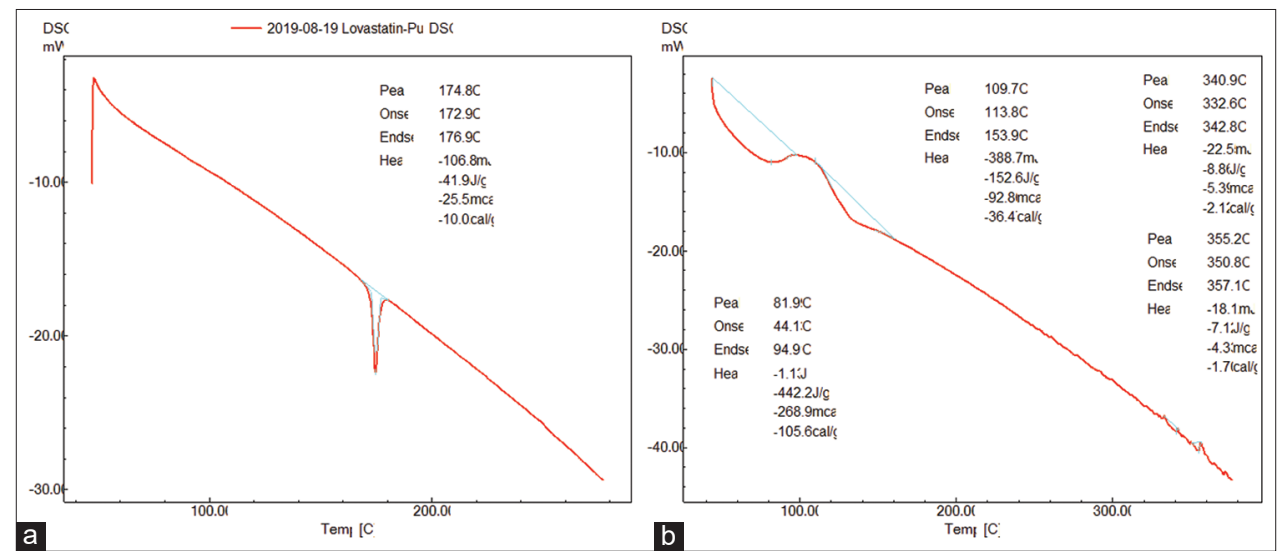

Fig. 5: (a and b) Differential scanning calorimetry thermogram of pure lovastatin (left spectra) and optimized batch (right spectra)

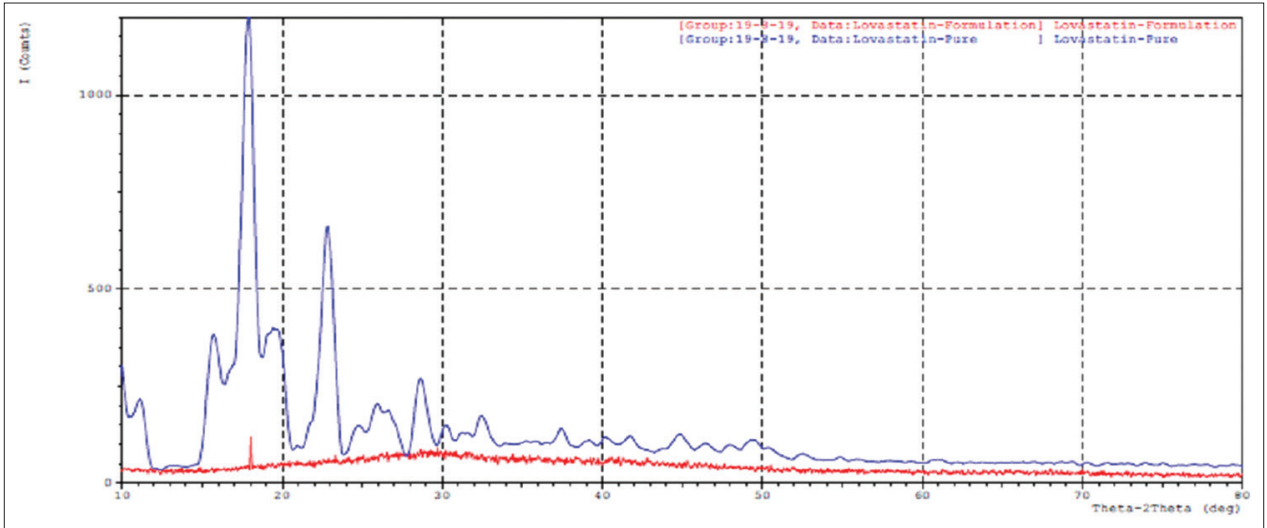

Fig. 6: X-ray diffraction spectra of pure lovastatin drug (above spectra) and optimized formulation of lovastatin (below spectra)

$109.7^{\circ} \mathrm{C}$ with peak of pure drug at $174.8^{\circ} \mathrm{C}$ and shifted slightly to left revealed that lovastatin existed in HPMC K4M beads in uncrystallized form.The less sharp endothermic peak is an indication of decrease in the crystalline state (i.e., conversion has took place to amorphous form). The amorphous nature results in higher solubility of pure drug and same in dissolution rate was observed. This indicates no chemical or physical interaction between the lovastatin and the polymer structure (Fig. 5).

\section{XRD studies}

In following, XRD spectra comparison pure drug and optimized are compared and it was found that the intensity of peaks of pure lovastatin is sharper than that of the drug in polymer matrix. The diffraction spectra of pure lovastatin showed more sharp and height in intensity of peaks indicates that the drug exist in crystalline state. This change (loss of sharpness) was given an indication of decreased the crystalline of pure drug in optimized batch and gives information of drug was dispersed uniformly in optimized batch and conversion has took place by converting crystal nature to amorphous nature. Thus, less intense peak in height in optimized as compared to pure drug indicates amorphous nature (Fig. 6) and it leads to results in higher solubility and dissolution rate as compared to pure drug.

Numerous prominent diffraction peaks of pure lovastatin were observed indicating the presence of crystalline nature. Lovastatin exhibited characteristic intense peaks between the $2 \theta$ of 11.2095, 15.7200, $17.8392,19.4400,21.6800,22.8155,24.7000,25.9200,26.6000$, $28.6533,30.2100,31.1800,32.4753,37.4133,41.6800,44.800$, and 49.3550 was appeared and suggesting crystalline nature of drug.

The in vitro wash-off studies

The in vitro wash-off test was done with simple modification of disintegration test apparatus and taken exact number of 100 lovastatin based alginate beads and placed/spread uniformly over mucous tissue specimen and run disintegration test continuously up to $8 \mathrm{~h}$ period. During study the beads which lack in mucoadhesive strength will detach from the surface of the mucous tissue specimen easily and drop in beaker and on continuous monitoring with respect to the time only few microbeads will be attached/adhered to the tissue specimen which was taken into final consideration as a best optimized batch. This test was done in both acidic and alkaline buffers continuously for $8 \mathrm{~h}$. In acidic medium more number of beads will drop down and will not adhere much to the tissue in all batches but in comparison to the same beads while test in phosphate buffer, $\mathrm{pH} 6.8$ much number of beads adhere to the mucous tissue in entire test period. Only LF8 batch (67 beads out of hundred) will retain more number of beads on tissue specimen even after a period of $8 \mathrm{~h}$ study against to LF17 (53 microbeads) and LF18 batch (43 microbeads) in 6.8 phosphate buffer medium and it was showed in Table 4, so of all above three batches only LF8 batch microbeads only forms maximum adhesive strength of microbeads which is why taken into best optimized batch finally in terms of mucoadhesive strength and maximum rate of swelling observed in alkaline medium (due to ionization of alginic acid which renders rapid swelling) rather than in acidic medium (less swelling capacity). Because more amounts of polymer mixture $(3 \% \mathrm{w} / \mathrm{v})$ results in higher amount of free - $\mathrm{COOH}$ groups, which are mainly responsible for binding with sialic acid groups in mucus membrane part and thus results in improvement in mucoadhesive properties of microspheres, while in acidic environment alginate microspheres shrink due to tightening of the gel meshwork. At 6.8 phosphate buffer atmosphere polymer mixture is eroded and the drug contents were released in a sustained manner by both process of diffusion and slow erosion of added polymer matrix.

\section{Dissolution studies}

Drug release studies were done using dissolution test apparatus (USP model TDT-08L) with paddle method. Equivalent amount of $20 \mathrm{mg}$ of lovastatin microbeads was placed in basket in form of tablet. 
Table 4: In vitro wash-off test values for the lovastatin sodium alginate microbeads prepared with equal combination of sodium alginate and hydroxypropyl methylcellulose $\mathrm{K} 4 \mathrm{M}$ in 1:3 ratios by employing $\mathrm{Alcl}^{3+}$ as a cross-linking agent

\begin{tabular}{|c|c|c|c|c|c|c|c|c|c|c|}
\hline \multirow[t]{3}{*}{ Formulation } & \multicolumn{10}{|c|}{ Percent of alginate beads adhering to tissue } \\
\hline & \multicolumn{5}{|c|}{0.1 N HCL. pH 1.2} & \multicolumn{5}{|c|}{ Phosphate buffer, pH 6.8} \\
\hline & 1 & 2 & 4 & 6 & 8 & 1 & 2 & 4 & 6 & 8 \\
\hline LF8 & $68(1.5)$ & $52(1.8)$ & $47(1.2)$ & $37(1.8)$ & $20(2.0)$ & $96(0.5)$ & $89(1.0)$ & $77(1.0)$ & $72(1.0)$ & $67(1.0)$ \\
\hline LF17 & $66(1.0)$ & $49(1.8)$ & $32(1.1)$ & $26(1.5)$ & $19(1.0)$ & $92(0.5)$ & $83(1.0)$ & $74(1.2)$ & 65 (1.8) & $53(1.2)$ \\
\hline LF18 & $64(1.8)$ & $43(1.2)$ & $32(1.8)$ & $24(2.0)$ & $15(1.8)$ & $90(0.5)$ & 77 (1.0) & 65 (1.5) & $51(1.5)$ & $43(2.0)$ \\
\hline
\end{tabular}

*All readings were taken in triplicate, i.e., $\mathrm{n}=3$. Mean \pm standard deviation

The dissolution studies were done continuously release up to $12 \mathrm{~h}$ without nonstop in between. The drug release study which is takes place in first $2 \mathrm{~h}$. in $0.1 \mathrm{~N}$ Hydrochloric acid and then remaining study continued with replacement of previous buffer solution with freshly prepared 6.8 phosphate buffer solution under and paddle speed is fixed at $100 \mathrm{rpm}$ at temperature of $37 \pm 0.5^{\circ} \mathrm{C}$. At low concentration of sodium alginate, i.e., 1.1 .5 and $2 \% \mathrm{w} / \mathrm{v}$, the orientation of polymeric system is loose with a greater hydrodynamic free volume which enables a greater amount of the fluid to be assimilated and it enables a higher rate of swelling. This, in turn, it encourages diffusion of the drug particle through the matrix system and causes a higher amount of drug discharge. In contrast to this, at higher concentration (3\% $\mathrm{w} / \mathrm{v}$ ), the physical mixture becomes higher viscosity and it promotes greater number of active binding sites along sodium alginate chain on cross-linking with aluminum chloride, finally it forms tight compact network and beads will produce with higher denser and rigid surface formed on their surfaces which restricts the entry of dissolution medium into network of alginate beads that lead to delay the drug release for a period up to $12 \mathrm{~h}$.

At low $\mathrm{pH}(0.1 \mathrm{~N} \mathrm{HCL})$, the number of positively charged ions is high, and they decrease the electrical repulsion between the negatively charged sodium alginate molecules. Sodium alginate is protonated into the insoluble form of alginic acid ions. Thus, migration of dissolution fluid (buffer solution) through the polymer matrix is restricted, and the percentage of drug released due to diffusion through the polymer network was minimal at $\mathrm{pH} 1.2$ for all prepared lovastatin microbeads. When $\mathrm{pH}$ is increased (6.8 $\mathrm{pH}$ phosphate buffer), drug release is enhances up to extreme level. The deprotonation of alginic acid happens at higher $\mathrm{pH}$ values (alkaline atmosphere). It will draw dissolution fluid into the microbeads, which causes more swelling of beads and burst apart of lovastatin drug.

This increased viscosity also affects the pore size on surface of beads and thus drug release becomes slowly and shows sustained in manner ( $3 \%$, sodium alginate: HPMC K4M. LF8 batch) than compared to LF17 and LF18 batches. The release behavior of alginate beads produced by ionic gelation with different cross-linking agents depends on the most of valence of ions $[21,22]$. Barium chloride (LF17) and calcium chloride (LF18) release drug to a lesser extent as compared to formulate the beads with sodium alginate with HPMC K4M in equal proportion at $3 \mathrm{w} / \mathrm{v}$ with aluminum chloride at $5 \% \mathrm{w} / \mathrm{w}$ (LF8) as a curing agent.

A variety of polymers have been used in this studies which include HPMC K4M, Carbopol 943P, and Na. Carboxymethyl cellulose in conjunction with sodium alginate in equal proportions with different curing agents naming aluminum chloride (LF8), barium chloride (LF17), and calcium chloride (LF18) at same concentration, i.e., $5 \% \mathrm{w} / \mathrm{v}$ to modulate drug loading, shape, surface, and drug release kinetics profile in sustained manner $[23,24]$. After $2 \mathrm{~h}$ of dissolution studies, drug release in $0.1 \mathrm{~N}$ HCL buffer medium was found to be at rate of $16.64 \pm 0.05$ for LF8, $20.46 \pm 0.03$ for LF17, and $20.97 \pm 0.03$ for LF18, respectively, under standard conditions. The drug release in case of LF8 batch was occurred and extended up to $12 \mathrm{~h}$ and drug release rate was found to be $99.35 \pm 0.08$ than comparison to the both LF17 and LF18 batches. The batch LF17 cured with barium chloride release the drug $99.89 \pm 0.03$ by end of $11 \mathrm{~h}$ only and LF18 batch cured with calcium chloride at $5 \% \mathrm{w} / \mathrm{v}$ level ended the drug release of $99.70 \pm 0.03$ by $10.5 \mathrm{~h}$ only. Based on above statistical data, the percentage of cumulative drug release was more in alkaline medium (6.8 phosphate buffer) and this depends on protonation of sodium alginate. This clearly denotes drug release of microbeads is $\mathrm{pH}$-dependent completely.

In initial span of $2 \mathrm{~h}$. The intensity of swelling of beads is to a minimum extent in the presence of acidic medium, which is due to alginate was protonated into insoluble form of alginic acid and the creation of intermolecular and intra molecular hydrogen bonding between the two used polymers, the less swelling should reduce the matrix permeability and limit the drug diffusion at acidic atmosphere and the force of $\mathrm{H}_{2}$ bond is more noteworthy than the repulsive forces, the microbeads are kept in a contracted state in acidic medium, and the alginate microspheres shrink due to tightening of the gel meshwork and the drug is discharged slowly. The rate of swelling is significantly increased than acidic medium (0.1N HCL). Swelling is straightforwardly corresponding to the drug discharge. The swelling capacity of ionic cross-connected microspheres is relying on the $\mathrm{pH}$ value of the swelling medium. From the above information, it was presumed that the measure of release of drug with respect to time is function of $\mathrm{pH}$ premises.

Under alkaline atmosphere conditions, i.e., at 6.8 phosphate buffer, the polymer is eroded at alkaline $\mathrm{pH}$ and the contents are released in a sustained manner by both diffusion and slow erosion of polymer matrix completely [25] deprotonation of alginic acid took place and initiate disintegration of the cross-linked bead systems, and it was associated that there was a breakage of hydrogen bond which lessens the interaction between the ionization of carboxylic group of alginate and the polyelectrolyte which brings about to promote in rate of swelling of lovastatin based alginate microbeads network with succeeding uptake of fluid and dissolution of drug pursued by drug release occurs by diffusion mechanism. Each reading was taken as the average of three. Nonetheless, at higher concentrations, the polymer chains trap to a more prominent degree culminating in "virtual cross-connecting" and in this manner the formation of a stronger medium compact gel layer. The plot of cumulative drug release (\%) against time (h.) is plotted all the batches and presented in Figs. 7-10. The release studies were directed in triplicate $(n=3)$.

After complete dissolution profile was done up to $12 \mathrm{~h}$ and in vitro wash-off studies with all three batches, i.e., LF8, LF17, and LF18 and on analyzing the data only LF8 batch could provide sustained release pattern than comparison to remaining two batches that formulated with same core: coat composition (drug:sodium alginate with HPMC $\mathrm{K} 4 \mathrm{M}, 1.5+1.5 \% \mathrm{w} / \mathrm{v}$., i.e., equal proportion of polymer mixture) but differ in selection of curing agent. Of all above-mentioned three batches only LF8 batch that cured with $5 \% \mathrm{w} / \mathrm{v}$ of $\mathrm{Alcl}^{3+}$ gives drug release in sustained release manner over a period of time up to $12 \mathrm{~h}$ and good mucoadhesive strength which was confirmed by conducting in vitro wash-off test up to $8 \mathrm{~h}$ duration of time (Table 4). This optimized batch was compared with pure lovastatin and marketed brand in terms of cumulative percentage drug release and which is shown in Fig. 10. Pure drug releases $85.64 \pm 1.023$ within $1.5 \mathrm{~h}$ whereas marketed brand release drug only $56.83 \pm 1.032 \%$ and it was extended up to 90 min only. Hence, 


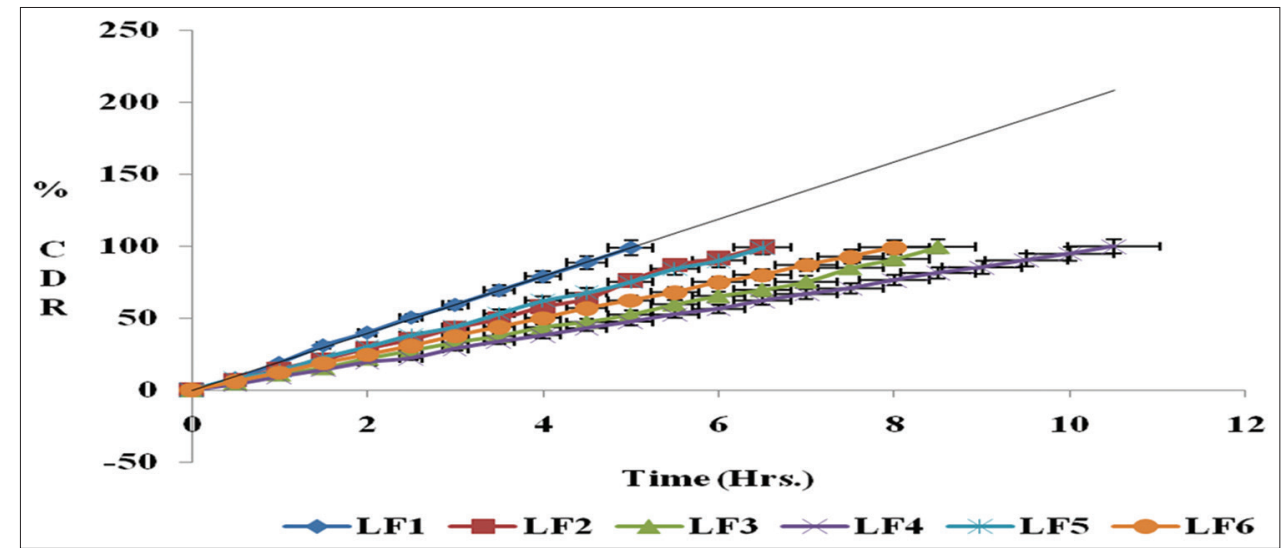

Fig. 7: Dissolution profile of batches from LF1 to LF6. Each value taken in mean \pm standard deviation, $n=3$

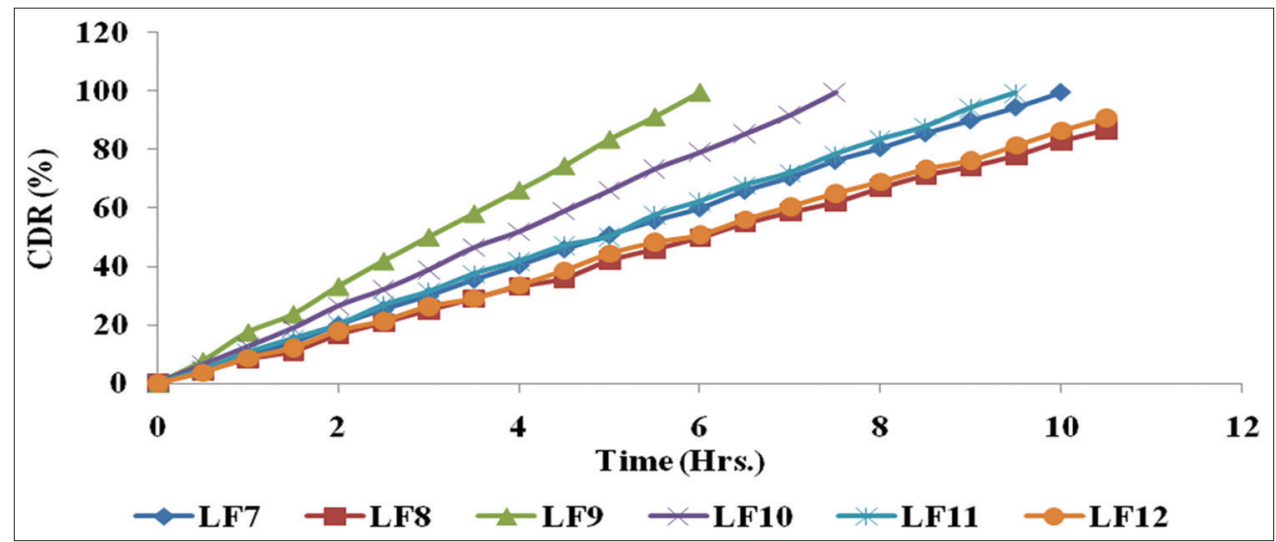

Fig. 8: Dissolution profile of batches from LF7 to LF12 (mean \pm standard deviation, $n=3$ )

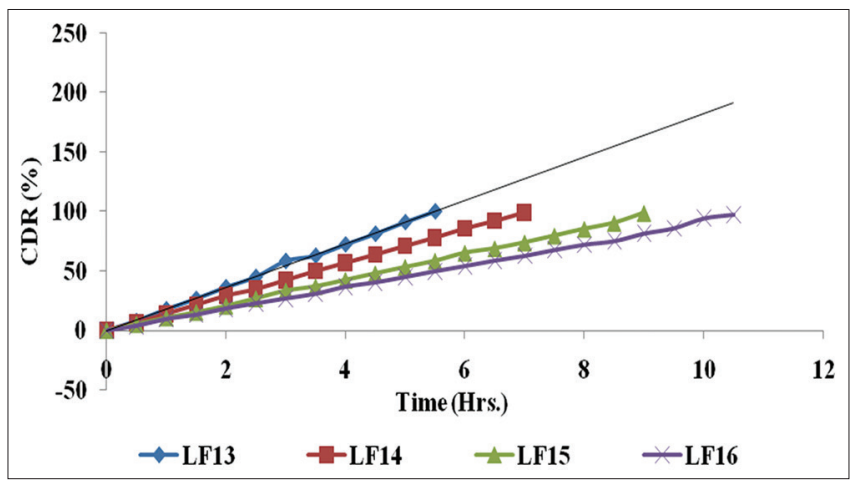

Fig. 9: Dissolution profile of batches from LF13 to LF16 (mean \pm standard deviation, $n=3$ )

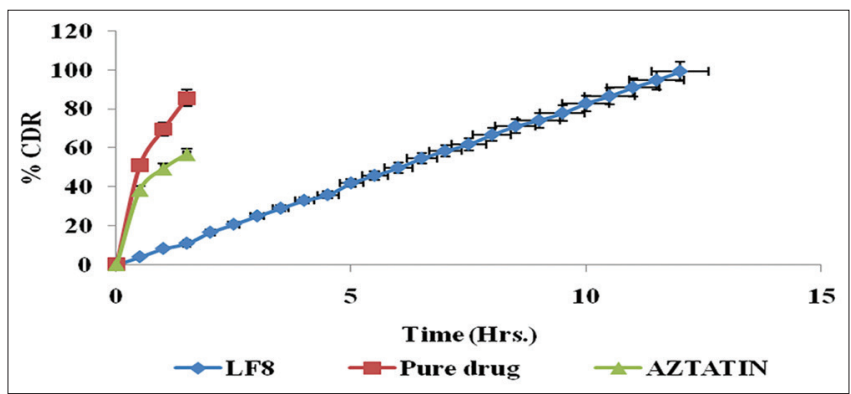

Fig. 10: Dissolution profile of optimized batch (LF8), pure drug and market brand. *Each value taken in triplicate (mean \pm standard deviation, $\mathrm{n}=3$ ) based on above data on comparison of all three batches, only LF8 batch could provide the drug release up to $12 \mathrm{~h}$ in sustained released manner and it minimizes the frequency of drug administration, improves the rate of bioavailability, reduces the incidence of side effects and toxic effects, and highly it improves patient compliance.

\section{Kinetic modeling}

Kinetic modeling in vitro dissolution data [26] were analyzed by different kinetic models to find out the n-value, which describes the drug release mechanism. The value of exponent $n$-value for optimized batch LF8 was found to be the 1.0168. The values of coefficient of correlation $\left(\mathrm{R}^{2}\right)$ obtained for the respective model are listed in following Table 5. If $\mathrm{n}>1.0$, at that point, it is affirmed as super Case II transport or non-Fickian diffusion, indicating that the drug release from LF8 batch microbeads followed the anomalous transport and super Case-II transport mechanism controlled by both swelling and relaxation of the polymer chains. The value of diffusion exponent " $n$ " for all batches was ranges from 0.8801 to 1.0725 .

\section{Stability studies}

According to ICH guidelines, stability studies were conducted by storing the optimized batch sample at room temperature $\left(25 \pm 2^{\circ} \mathrm{C} / 60 \pm 5 \% \mathrm{RH}\right)$ and accelerated condition $\left(40 \pm 2^{\circ} \mathrm{C} / 75 \pm 5 \% \mathrm{RH}\right)$ for 3 months. The results after 3 months and they show in the following Table 6, and results revealed that prepared cross linked beads of lovastatin stable for a 3 months period of time and not observed any significant changes in physical, drug content, drug entrapment, and drug release studies during stability studies. About drug content and percentage drug entrapment efficiency values observed after 3 months stability studies under standard conditions do not showed any marked changes (Table 7) and said to be they all stable in all different atmospheric conditions. Each reading were taken in triplicate manner, i.e., $n=3$. 
Table 5: In vitro dissolution kinetics parameters of lovastatin microbeads prepared with sodium alginate alone and in combination of sodium alginate with hydroxypropyl methylcellulose $\mathrm{K} 4 \mathrm{M} / \mathrm{Carbopol} 934 \mathrm{P} / \mathrm{Na}$. Carboxymethyl cellulose in different ratios by employing aluminum chloride/barium chloride/calcium chloride as a cross-linking agent at $5 \% \mathrm{w} / \mathrm{v}$

\begin{tabular}{|c|c|c|c|c|c|c|c|c|}
\hline \multirow[t]{2}{*}{ Formulation } & \multicolumn{4}{|c|}{ Correlation coefficient $\left(\mathrm{R}^{2}\right)$} & \multicolumn{3}{|c|}{ Release kinetics } & \multirow{2}{*}{$\begin{array}{l}\text { Diffusion } \\
\text { exponent value (n) }\end{array}$} \\
\hline & Zero-order & First-order & Higuchi & Peppas & $K_{o}(\mathrm{mg} / \mathrm{h})$ & $T_{50}(h)$ & $T_{90}(h)$ & \\
\hline LF1 & 0.9997 & 0.9341 & 0.9924 & 0.9983 & 4.0 & 2.5 & 4.6 & 1.0725 \\
\hline LF3 & 0.9995 & 0.9283 & 0.9864 & 0.9995 & 2.12 & 4.7 & 8.4 & 1.0106 \\
\hline LF4 & 0.9998 & 0.9222 & 0.9993 & 0.9968 & 1.88 & 5.3 & 9.5 & 1.0337 \\
\hline LF5 & 0.9999 & 0.9433 & 0.9877 & 0.9999 & 3.03 & 3.3 & 5.9 & 1.0091 \\
\hline LF6 & 0.9999 & 0.9340 & 0.9879 & 0.9999 & 2.5 & 4.0 & 7.2 & 1.0544 \\
\hline LF7 & 0.9998 & 0.9254 & 0.9877 & 0.9998 & 2 & 5.0 & 9.0 & 1.0248 \\
\hline LF8 & 0.9997 & 0.9289 & 0.9862 & 0.9995 & 1.65 & 6.0 & 10.9 & 1.0168 \\
\hline LF9 & 0.9998 & 0.9405 & 0.9883 & 0.9992 & 3.33 & 3.0 & 5.4 & 1.0212 \\
\hline LF10 & 0.9999 & 0.9396 & 0.9865 & 0.9999 & 2.63 & 3.8 & 6.8 & 1.0181 \\
\hline LF11 & 0.9997 & 0.9266 & 0.9860 & 0.9995 & 2.08 & 4.8 & 8.7 & 1.0188 \\
\hline LF12 & 0.9996 & 0.9233 & 0.9864 & 0.9992 & 1.72 & 5.8 & 10.5 & 1.0245 \\
\hline LF13 & 0.9991 & 0.9383 & 0.9901 & 0.9991 & 3.57 & 2.8 & 5.0 & 1.0368 \\
\hline LF14 & 0.9999 & 0.9369 & 0.9877 & 0.9998 & 2.85 & 3.5 & 6.3 & 1.0101 \\
\hline LF15 & 0.9996 & 0.9346 & 0.9852 & 0.9998 & 2.12 & 4.7 & 8.4 & 1.0070 \\
\hline LF17 & 0.9978 & 0.7113 & 0.9208 & 0.9963 & 1.78 & 5.60 & 10.08 & 0.8801 \\
\hline LF18 & 0.9920 & 0.7456 & 0.9032 & 0.9931 & 2.27 & 4.40 & 7.92 & 0.9023 \\
\hline
\end{tabular}

Table 6: In vitro dissolution data of optimized batch containing lovastatin microbeads stored at $25 \pm 2{ }^{\circ} \mathrm{C} / 60 \pm 5 \% \mathrm{RH}$ and $40 \pm 2{ }^{\circ} \mathrm{C} / 75 \pm 5 \%$ RH after 3 months of stability studies

\begin{tabular}{|c|c|c|c|c|c|c|c|c|}
\hline \multirow{3}{*}{$\begin{array}{l}\text { S. } \\
\text { No. }\end{array}$} & \multirow[t]{3}{*}{ Time (h.) } & \multirow[t]{3}{*}{ Initial } & \multicolumn{6}{|c|}{ Percentage of lovastatin released (mean \pm SD) } \\
\hline & & & \multicolumn{3}{|c|}{$25 \pm 2^{\circ} \mathrm{C} / 60 \pm 5 \% \mathrm{RH}$} & \multicolumn{3}{|c|}{$40 \pm 2^{\circ} \mathrm{C} / 75 \pm 5 \% \mathrm{RH}$} \\
\hline & & & $1^{\text {st }}$ month & $2^{\text {nd }}$ month & $3^{\text {rd }}$ month & $1^{\text {st }}$ month & $2^{\text {nd }}$ month & $3^{\text {rd }}$ month \\
\hline 1. & 0 & 0 & 0 & 0 & 0 & 0 & 0 & 0 \\
\hline 2. & 0.5 & $04.01 \pm 0.05$ & $3.84 \pm 0.09$ & $3.76 \pm 0.13$ & $3.67 \pm 0.06$ & $3.72 \pm 0.13$ & $3.64 \pm 0.08$ & $3.55 \pm 0.05$ \\
\hline 3. & 1.0 & $08.27 \pm 0.07$ & $7.93 \pm 0.14$ & $7.86 \pm 0.06$ & $7.75 \pm 0.13$ & $7.81 \pm 0.11$ & $7.73 \pm 0.09$ & $7.66 \pm 0.08$ \\
\hline 4. & 1.5 & $10.99 \pm 0.04$ & $10.57 \pm 0.10$ & $10.48 \pm 0.08$ & $10.40 \pm 0.09$ & $10.45 \pm 0.14$ & $10.39 \pm 0.11$ & $10.13 \pm 0.05$ \\
\hline 6. & 2.5 & $20.73 \pm 0.07$ & $20.16 \pm 0.15$ & $20.07 \pm 0.09$ & $20.98 \pm 0.09$ & $20.06 \pm 0.05$ & $20.97 \pm 0.11$ & $20.85 \pm 0.10$ \\
\hline 7. & 3.0 & $25.03 \pm 0.04$ & $24.93 \pm 0.13$ & $24.86 \pm 0.11$ & $24.74 \pm 0.15$ & $24.99 \pm 0.13$ & $24.82 \pm 0.06$ & $24.74 \pm 0.13$ \\
\hline 8. & 3.5 & $29.01 \pm 0.05$ & $28.92 \pm 0.09$ & $28.83 \pm 0.13$ & $28.73 \pm 0.09$ & $28.39 \pm 0.09$ & $28.32 \pm 0.08$ & $28.25 \pm 0.11$ \\
\hline 9. & 4.0 & $33.06 \pm 0.07$ & $32.73 \pm 0.06$ & $32.64 \pm 0.15$ & $32.54 \pm 0.06$ & $32.59 \pm 0.15$ & $32.53 \pm 0.13$ & $32.46 \pm 0.09$ \\
\hline 10. & 4.5 & $35.90 \pm 0.06$ & $35.86 \pm 0.08$ & $35.81 \pm 0.06$ & $35.77 \pm 0.08$ & $35.82 \pm 0.13$ & $35.74 \pm 0.09$ & $35.65 \pm 0.08$ \\
\hline 11. & 5.0 & $41.96 \pm 0.06$ & $41.22 \pm 0.10$ & $41.13 \pm 0.09$ & $41.02 \pm 0.13$ & $41.09 \pm 0.10$ & $41.02 \pm 0.15$ & $41.94 \pm 0.06$ \\
\hline 12. & 5.5 & $45.84 \pm 0.08$ & $45.49 \pm 0.08$ & $45.40 \pm 0.05$ & $45.30 \pm 0.06$ & $45.37 \pm 0.05$ & $45.31 \pm 0.10$ & $45.27 \pm 0.09$ \\
\hline 13. & 6.0 & $49.81 \pm 0.07$ & $49.80 \pm 0.11$ & $49.71 \pm 0.06$ & $49.60 \pm 0.11$ & $49.66 \pm 0.11$ & $49.59 \pm 0.06$ & $49.43 \pm 0.11$ \\
\hline 15. & 7.0 & $58.49 \pm 0.05$ & $58.47 \pm 0.09$ & $58.39 \pm 0.11$ & $58.26 \pm 0.15$ & $58.32 \pm 0.05$ & $58.26 \pm 0.06$ & $57.97 \pm 0.13$ \\
\hline 16. & 7.5 & $61.90 \pm 0.09$ & $61.84 \pm 0.13$ & $61.76 \pm 0.08$ & $61.63 \pm 0.09$ & $61.69 \pm 0.15$ & $61.61 \pm 0.13$ & $61.54 \pm 0.15$ \\
\hline 17. & 8.0 & $66.79 \pm 0.05$ & $66.22 \pm 0.11$ & $66.13 \pm 0.10$ & $66.02 \pm 0.06$ & $66.09 \pm 0.09$ & $66.03 \pm 0.11$ & $66.94 \pm 0.10$ \\
\hline 18. & 8.5 & $71.17 \pm 0.06$ & $70.64 \pm 0.14$ & $70.54 \pm 0.13$ & $70.45 \pm 0.11$ & $70.51 \pm 0.06$ & $70.44 \pm 0.08$ & $70.37 \pm 0.11$ \\
\hline 19. & 9.0 & $74.18 \pm 0.03$ & $74.08 \pm 0.12$ & $73.99 \pm 0.09$ & $73.90 \pm 0.09$ & $73.99 \pm 0.08$ & $73.92 \pm 0.09$ & $73.57 \pm 0.13$ \\
\hline 20. & 9.5 & $77.90 \pm 0.05$ & $77.54 \pm 0.15$ & $77.43 \pm 0.06$ & $77.32 \pm 0.06$ & $77.37 \pm 0.09$ & $77.31 \pm 0.11$ & $77.43 \pm 0.15$ \\
\hline 21. & 10 & $82.89 \pm 0.03$ & $82.07 \pm 0.13$ & $81.91 \pm 0.08$ & $81.80 \pm 0.08$ & $81.86 \pm 0.05$ & $81.80 \pm 0.09$ & $81.73 \pm 0.09$ \\
\hline 22. & 10.5 & $86.62 \pm 0.04$ & $86.52 \pm 0.10$ & $86.44 \pm 0.15$ & $86.31 \pm 0.13$ & $86.38 \pm 0.06$ & $86.32 \pm 0.10$ & $86.26 \pm 0.10$ \\
\hline 23. & 11 & $91.10 \pm 0.08$ & $91.07 \pm 0.11$ & $90.95 \pm 0.10$ & $90.83 \pm 0.10$ & $90.89 \pm 0.10$ & $90.83 \pm 0.13$ & $90.76 \pm 0.13$ \\
\hline 24. & 11.5 & $94.82 \pm 0.04$ & $94.33 \pm 0.13$ & $94.25 \pm 0.09$ & $94.16 \pm 0.14$ & $94.21 \pm 0.15$ & $94.16 \pm 0.09$ & $94.08 \pm 0.15$ \\
\hline 25. & 12 & $99.35 \pm 0.08$ & $99.30 \pm 0.10$ & $99.22 \pm 0.11$ & $99.12 \pm 0.13$ & $99.09 \pm 0.09$ & $98.73 \pm 0.06$ & $98.66 \pm 0.08$ \\
\hline
\end{tabular}

*Each reading in triplicate manner mean \pm standard deviation

Table 7: Drug content, encapsulation efficiency, and dissolution kinetics of cross-linked lovastatin microbeads stored after 3 months at $25 \pm 2^{\circ} \mathrm{C} / 60 \pm 5 \% \mathrm{RH}$ and $40 \pm 2^{\circ} \mathrm{C} / 75 \pm 5 \% \mathrm{RH}$

\begin{tabular}{|c|c|c|c|c|c|c|}
\hline Storage conditions & Time interval & Drug content & Encapsulation efficiency & Release rate constant $(\mathrm{mg} / \mathrm{h}) \mathrm{K}_{\mathrm{o}}$ & $\mathbf{t}_{50 \%}$ & $t_{90 \%}$ \\
\hline \multirow[t]{3}{*}{$25 \pm 2^{\circ} \mathrm{C} / 60 \pm 5 \% \mathrm{RH}$} & $1^{\text {st }}$ month & 24.11 & 96.44 & 1.65 & 6.0 & 10.9 \\
\hline & $2^{\text {nd }}$ month & 24.10 & 96.50 & 1.65 & 6.0 & 10.9 \\
\hline & $3^{\text {rd }}$ month & 24.08 & 96.32 & 1.65 & 6.0 & 10.9 \\
\hline \multirow[t]{3}{*}{$40 \pm 2^{\circ} \mathrm{C} / 75 \pm 5 \% \mathrm{RH}$} & $1^{\text {st }}$ month & 24.09 & 96.36 & 1.65 & 6.0 & 10.9 \\
\hline & $2^{\text {nd }}$ month & 24.07 & 96.28 & 1.65 & 6.0 & 10.9 \\
\hline & $3^{\text {rd }}$ month & 24.06 & 96.24 & 1.65 & 6.0 & 10.9 \\
\hline
\end{tabular}

*Each reading in triplicate manner, i.e., $\mathrm{n}=3$ 


\section{CONCLUSION}

Lovastatin microbeads were prepared for the sustained release using the sodium alginate as a major polymer and in later it combined with hydrophilic polymer to improve entrapment and sustained release of the drug from alginates beads. It also depends on using different divalent and trivalency cross-linking agents it is possible to improve drug entrapment efficiency, maximum drug release from the beads at extended period of time. By addition of combination of polymers it is also possible to promote adhesion of alginate beads to gastric mucosa, which enables to cause to release drug in sustained release and for extended release of time. Various batches as well as other process variables affect the shape, size, and mucoadhesion strength and to modify drug release pattern of obtained microbeads. Stability studies were conducted to evaluate the performance of drug release, DEE, shape as per the ICH guidelines and it has proved that the prepared microbeads not undergone any changes even after stability study done for 3 months. In vitro drug release, the alginate-lovastatin microbeads prepared with HPMC K4M using aluminum chloride shows promising carrier more sustained action than barium and calcium chloride used as cross-linked agents at the same concentrations. It was found to be drug release is $\mathrm{pH}$ dependent. The microbeads showed very high release of drug at $\mathrm{pH} 6.8$ than in comparison to acidic medium. The release of drug from microbeads is followed by swelling and relaxation of polymer chain in buffer medium. This will be an advantage in overcoming the drawbacks of lovastatin with short half-life and improves the bioavailability rate. The release kinetics of drug from the alginate beads followed zero-order ( $\mathrm{R}^{2}$ value was above 0.90 for all batches).

\section{ACKNOWLEDGMENT}

The authors thank Aurobindo Pharmaceuticals, Hyderabad, Telangana State, India, for providing lovastatin as a gift sample for completion of this work and extending special thanks to Osmania University, Hyderabad, for allowing samples to analytical studies.

\section{AUTHOR'S CONTRIBUTIONS}

Venkata Ramana Reddy KV has compiled the whole manuscript, Dr. Sai Kishore has generated the idea, and Dr. Loya helped me in the compilation of Research Manuscript and both provided necessary guidance while making compilation, and Dr. Anup helped in reducing the plagiarism and check spelling while drafting the manuscript and provided all full-text literature in arrangement style.

\section{CONFLICTS OF INTEREST}

The authors declared that they have no conflicts of interest.

\section{REFERENCES}

1. Praveen N, Mahant S, Sharma D. Review: Floating systems: A novel approach towards gastro retentive drug delivery systems. Int J Pharm Pharm Sci 2010;2:2-8.

2. Yellela S, Krishnaiah R, Pharmaceutical Technologies for enhancing oral bioavailability of poorly soluble drugs. J Bioequivalence Bioavailabl 2010;2:28-36.

3. Hassan M, Jafar M. Improving dissolution of meloxicam using solid dispersions. Iran J Pharm Res 2010;4:231-8.

4. Jammula S, Patra CN, Swain S, Panigarhi KC, Patro AP, Sarwar B, et al. Improvement in the dissolution rate and tableting properties of cefuroxime axetil by melt-granulated dispersion and surface adsorption. Acta Pharm Sin B 2013;2:113-22.

5. Jenkins DJ, Kendall CW, Marchie A, Faulkner DA, Wong JM, de
Souza R, et al. Effects of a dietary portfolio of cholesterol-lowering foods vs lovastatin on serum lipids and C-reactive protein. JAMA 2003;290:502-10.

6. Wong SM, Kellaway IW, Murdan S. Enhancement of the dissolution rate and oral absorption of a poorly water soluble drug by formation of surfactant-containing microparticles. Int J Pharm 2006;317:61-8.

7. Ajit SK, Nagesh H, Madhav S. Liquisolid systems. Int J Pharm Sci Nanotech 2010;3:795-802.

8. Lennernäs H, Fager G. Pharmacodynamics and pharmacokinetics of the HMG-coA reductase inhibitors. Similarities and differences. Clin Pharmacokinet 1997;32:403-25.

9. Verma JB, Naik VJ. Mokale. Am J Pharm Sci Nanotech 2014;1:11-26.

10. Smrdel P, Bogataj M, Mrhar A. The influence of selected parameters on the size and shape of alginate beads prepared by ionotropic gelation. Sci Pharm 2008;76:77-89.

11. Sun SB, Liu P, Shao FM, Miao QL. Formulation and evaluation of PLGA nanoparticles loaded capecitabine for prostate cancer. Int J Clin Exp Med 2015;8:19670-81.

12. Yadav SK, Mishra B. Preformulation studies on combination of ornidazole and doxycycline in pharmaceutical dosage forms: Infrared spectroscopy and simultaneous ultra-violet method development. J Chem Pharm Res 2016;8:564-73.

13. Ghaderi S, Ghanbarzadeh S, Hamishehkar H. Evaluation of different methods for preparing nanoparticle containing gammaoryzanol for potential use in food fortification. Pharm Sci 2015;20:130-4.

14. Mahajan HS, Gattani SG. Nasal administration of ondansetron using a novel microspheres delivery system part 2: Ex vivo and in vivo studies. Pharm Dev Technol 2010;15:653-7.

15. Chen H, Chang X, Weng T, Zhao X, Gao Z, Yang Y, et al. A study of microemulsion systems for transdermal delivery of triptolide. J Control Release 2004;98:427-36.

16. Sharma M, Choudhury PK, Kumar S. Formulation and in vitro in vivo evaluation of alginate-chitosan microspheres of glipizide by ionic gelation method. Asian J Pharm Clin Res 2017;10:385-90.

17. Nagarajana E, Shanmugasundarama $P$, Ravichandirana V, Vijayalakshmia A, Senthilnathan BK. Development and evaluation of chitosan based polymeric nanoparticles of an antiulcer drug lansoprazole. J Appl Pharm Sci 2015;5:20-5.

18. Surjyanarayan M, Hemangini R, Bhavdip J, Mikesh P, Rajesh KS. Release kinetic modeling of atorvastatin calcium loaded self-micro emulsifying drug delivery system. Elix Pharm 2012;53:11725-9.

19. Penman A, Sanderson GR. A method for the determination of uronic acid sequence in alginates. Carbohydr Res 1972;25:273-82.

20. Jahan ST, Sadat SM, Islam MR, Azam AT, Chowdhury JA. Effect of various electrolytes on theophylline loaded sodium alginate beads prepared by ionic cross linking technique. J Pharm Sci 2012;11:181-9.

21. Bajpai SK, Sharma S. Investigation of swelling/degradation behaviour of alginate beads crosslinked with $\mathrm{Ca}^{+2}$ and $\mathrm{Ba}^{+2}$ ions. React Funct Polym 2004;59:129-40.

22. Das MK, Senapati PC. Evaluation of furosemide-loaded alginate microspheres prepared by ionotropic external gelation technique. Acta Polym Pharm 2007;64:253-62.

23. Hua S, Ma H, Li X, Yang H, Wang A. pH-sensitive sodium alginate/ poly(vinyl alcohol) hydrogel beads prepared by combined $\mathrm{Ca}^{2+}$ crosslinking and freeze-thawing cycles for controlled release of diclofenac sodium. Int J Biol Macromol 2010;46:517-23.

24. Pillay V, Fassihi R. In vitro release modulation from cross-linked pellets for site-specific drug delivery to the gastrointestinal tract: I. Comparison of $\mathrm{pH}$-responsive drug release and associated kinetics. J Control Release 1999;59:229-42.

25. Choudhury PK, Panigrah GS, Pradhan KK, Panda CK, Pasa GS. Design, development and evaluation of furosemide loaded micropellets prepared by ionotropic gelation method. Int J Pharmtech Res 2010;2:420-6.

26. Reddy KV, Nagabhushanam MV. The Role of needle in formulation of $\mathrm{pH}$ sensitive swellable microbeads prepared with hydrophilic polymers for atorvastatin and their characterization studies. Int J App Pharm 2017;9:20-30. 